\title{
Mini-Review
}

\section{To name or not to name? An overview of the social and ethical issues raised by removing anonymity from sperm donors}

Jennifer A. Burr

University of Sheffield School of Health and Related Research, Sheffield SA1 4DA, UK

\begin{abstract}
The aim of this paper is to focus on the ethical issues raised by the removal of anonymity from sperm donors. The increasing currency of a 'right to genetic truth' is clearly visible in the drive to revise the legislation on donor anonymity in Western and European countries. The ethical debate is polarized between the 'right to privacy' of the donor or parent and the 'right to know' of the prospective child. However, it is evident that religious, social and cultural attitudes have an overarching impact on attitudes towards sperm donation generally and anonymity specifically. In Asian countries, the social and cultural heritage is hugely diverse and different from those of the West. This review considers the research exploring the complexity of ethical issues informing this debate, and argues that parent's decisions to reveal donor insemination origins to their children are highly complex and relate to a range of social and cultural attitudes that have not been addressed within the policy to remove anonymity from sperm donors.
\end{abstract}

Asian Journal of Andrology (2010) 12: 801-806. doi: 10.1038/aja.2010.60; published online 12 July 2010.

Keywords: anonymity, ethics, disclosure, genetic origins, secrecy, sperm donation

\section{Introduction}

Following on from Gong et.al. [1] and their overview of the ethical issues raised by sperm donation published in AJA 2009[1], the aim in this paper is to focus on the ethical issues specifically raised by the removal of anonymity from sperm donors. The ethical issues provoked by the removal of anonymity are still unresolved and raise concerns about the significance of genetic inheritance and the competing rights claims

Correspondence to: Dr Jennifer A. Burr, University of Sheffield School of Health and Related Research, Regent Court 30 Regents Street, Sheffield SA1 4DA, UK.

Fax: +44-0114-2724-095 E-mail: j.a.burr@sheffield.ac.uk

Received: 2 April 2010

Accepted: 31 May 2010
Revised: 13 May 2010

Published online: 12 July 2010 for, not just children, but also donors and the parents of donor insemination (DI) offspring. DI does not provide a cure for male infertility, but provides a method of circumventing the problem. Its uses have expanded more recently to provide for a male who is carrying a genetic disorder or in cases in which a woman wants to conceive without sexual intercourse with a man. From a medical perspective, the issues around DI are expressed in terms of diagnosis, success rates and recruitment of sperm donors [2]. However, DI is not only about becoming a parent and forming families but also about social relationships and processes that go beyond the practical issues. Sperm can be described, either as material of purely biological significance or as the potential for a family to be formed or deformed, and therefore of psychosocial significance [3]. It is argued here that it is at the level of the social significance of DI 
for families with DI children in which the ethical issues can be found.

Since the publication of Daniels and Haimes' [2] 'Donor Insemination International social science perspectives' in 1998, the importance of a social science perspective to understand some of the issues raised in DI has increasingly been recognized. From a clinical perspective, issues around DI are about diagnosis, treatment and how and when to advise DI. However, another perspective is to describe DI practice in reference to creating families, and, therefore, DI is also about creating and recreating social relationships and social processes. It is not that the two perspectives are exclusive, but that social science perspectives make explicit the wider sociocultural context of DI and the ethical decisions that govern the practice. Daniels and Haimes' collection was important in presenting the first systematic collection of work that documented and analysed the social relationships that influence DI, from a clinical and social perspective. In all, there has been a growing interest in the experiences of heterosexual couples who conceive using DI [4-7]. In addition, limited research has been carried out in single women and lesbian couples who use DI [8].

As a method of conception, DI transgresses conventional ideas, not just about conception but also about parenthood, family structure and kinship and paternity. It raises the potential for reproduction outside traditional gendered and heteronormative structures. Sperm donation effectively fills the biological reproductive role of the recipients' husband/male partner and has a sexual connotation that early commentaries likened to fornication and adultery [3]. It is perhaps not surprising, especially given the social significance of DI, that some religions find DI unacceptable, and in Asian countries, there is a clear division regarding attitudes to gamete donation, generally between Moslem and non-Moslem countries [9]. In most of the Moslem countries, gamete donation is banned. In China, Israel, Hong Kong (China), Singapore, Thailand, India and Israel, wherein gamete donation is practiced, sperm donors are anonymous [9]. In China, anonymous sperm donation remains important because of the significance of a child's genetic origin in Chinese culture and the preference not to disclose to safeguard the unity of the family [1].

In the United Kingdom, the recruitment of sperm donors follows the Human Fertilisation and Embryology Authority (1990) (the 1990 Act) Code of
Practice, which, in turn, follows the recommendations of the British Andrology Society, and includes policy on the screening details for family health and genetic history [10]. In the United Kingdom, before 2005, the donor was anonymous. The 1990 Act stated that personal identifying features of the donor could not be passed to either the parents receiving gametes or any potential offspring, although children born from donor gametes had limited statutory access to nonidentifying information. The legal principle of donor anonymity was originally formulated by the 1984 Report of the Committee of Inquiry into Human Fertilisation and Embryology, better known as the Warnock Report. This stated that a donor whose identity was known would potentially represent 'a third party into marriage' [11]. It was also argued in the Warnock Report that men would be considerably less likely to become donors without anonymity. The subsequent formulation of the 1990 Act also stated that donor anonymity provided statutory protection to the donor. In essence, anonymity ensured that the donor played no role in his genetic child's life and preserved the conventional features of the family by erecting a barrier around the unit [12].

In the United Kingdom, following a Department of Health review in 2005 , children conceived as a result of donated sperm can access information about their genetic origins after they reach the age of 18 years, and have the same right as adopted children to trace a biological parent. Although donors have no legal or financial responsibility for a child, the consequence of this change in policy has been linked to what has been termed a 'crisis' in gamete donation, with almost $10 \%$ of fertility clinics in the United Kingdom having no access to donor sperm or finding it extremely difficult to obtain it [13].

\section{Rights of the child}

The increasing currency of a 'right to genetic truth' was clearly visible in the drive to revise the legislation on donor anonymity in the United Kingdom [14]. The drive to revise legislation came from children born as a result of DI. In Rose $v$ Secretary of State for Health [2002] EWHC 1593, the High Court ruled that the Human Rights Act was a basis for donor offspring to seek nonidentifying information about their gamete donors. In Rose, the judge described how the claimants, in seeking knowledge of their genetic inheritance, are trying to obtain knowledge that 'goes to the very heart 
of their identity, and to their make up as people' [14]. The United Kingdom is not the only country to interpret a child's right in this way. For example, Austria's Medically Assisted Procreation Act 1992 has interpreted Article Seven of the Convention of the Rights of the Child, which incorporates the right to know one's parents, and Article Eight of the European Convention on Human Rights, the right to respect for family life, to mean that sperm donation should not be anonymous $[15,16]$. Both Western and South Australia, and Switzerland use the language of a child's right to know their biological origins [15]. Therefore, the two main arguments used to support why one is required to know one's genetic origins as a right are that it is thought to be essential to human well-being and that the individual has a right to know the truth about their origins and that it is harmful to donor offspring to be denied this right [17].

The implications for a child's right to know their genetic origins has far reaching implications, especially given the evidence that suggests that more than 1 in 25 families have children being raised by a father who is not genetically related to his children [18]. Furthermore, the evidence that harm may be caused by not knowing one's biological origins is drawn from the adoption literature and this raises questions about whether the argument can be applied to donor offspring. For example, adopted children are likely to be abandoned by their genetic parents and brought up by parents who are not genetically related to them. Donor offspring are very much wanted and are usually genetically related to one parent [19]. Certainly, studies conducted with children conceived through donor conception are inconclusive about the impact of not knowing the circumstances of one's conception and whether 'harm' results from a lack of such knowledge.

The removal of anonymity in the United Kingdom has not been generally well received by fertility experts and their professional bodies (the British Fertility Society; the British Medical Association; and the Royal College of Obstetricians and Gynecologists). Ostensibly, the main reasons for their views was that the removal of anonymity would aversely impact on the supply of willing sperm donors, and also that it would make it less likely that parents of donorconceived children would tell their children about the circumstances of their conception (BMA 2004). However, as Blyth and Frith [20] have argued, shortages of donor sperm are evident globally, including in jurisdictions in which donor anonymity continues to be practiced. In addition, although there is some evidence from jurisdictions that have removed anonymity from donors that the number of sperm donors has experienced a decline, this decline can be reversed [21]. Furthermore, there is no evidence from studies conducted with parents of donor-conceived children that the removal of anonymity would make it any less likely that parents would tell their children of the circumstances of their conception. Research conducted before removal of anonymity suggests that most children are ignorant of their donor offspring status [22-25]. Other European studies revealed that most couples did not intend to tell their children of their DI origins [26-28]. More recently, Golombok et al. [25], in a study of 94 families with children conceived by DI, found that only $8.6 \%$ of DI children had been informed about their genetic origins, compared with $50 \%$ of in vitro fertilization (IVF) parents and $95 \%$ of adoptive parents. At most, only basic donor information was deemed important (for example, ethnicity, hight, education and health information) [24, 29].

Therefore, the ethical concerns raised by removing anonymity from sperm donors seem to lie elsewhere, as an overview of the previous research on parent's perspectives seems to indicate.

\section{Parental preferences for anonymous donors}

Previous European research has revealed that parents have a strong preference for anonymous donors, and suggests that the majority of couples did not reveal DI conception to their offspring [30, 31]. In a study comparing DI and parents who had conceived through IVF, Brewaeys et al. [22] reported that most DI parents wanted an anonymous donor or would have liked only nonidentifying information about the donor (whereas IVF parents intended to inform their offspring of how they were conceived), identifying a major concern as the medical/genetic background of the donor. Fathers were more likely than mothers to prefer an anonymous donor, and more women than men opted for donor identification [22, 32]. Within lesbian mother families with DI children, the social mothers (the biological mother's partner) expressed the desire for an anonymous donor compared with the biological mothers, who would have wanted more information [33]. Brewaeys suggests that the parent who lacks a genetic relationship with the child may experience the donor as more threatening [22]. 
The reasons that parents give for not wanting to reveal DI origins to their children are revealed as complex in previous studies [34-39]. Research has revealed parental concerns about community attitudes, absence of genetic history and whether or how to explain the situation of their conception to their children [40]. Looi, in an Australian study [41], revealed that some DI parents were reluctant to tell children about their DI origins because of disruption to the family unit. Parents want to protect the male partner from the stigma of infertility, to protect family relationships and protect the child $[22,27,30]$.

There are powerful arguments against telling donor offspring about the conditions of their conception. These include that parents should have a right to keep such information a secret. It remains the case that none of the countries that endorse nonanonymous donation, including the United Kingdom, have instituted a formalized mechanism for ensuring that the child is informed [42]. In a recent UK study reported by Burr and Reynolds [39], for the parents interviewed in this study, 'rights' had a far broader application than a child's right to know. The best interests of the child were described by these parents, however, as being met through a number of means, which included, at one end of the spectrum, informing the child of their genetic inheritance, but which also justified withholding this information for other parents. In some circumstances, parents felt that revealing DI status to a child would be detrimental to their best interests. The concern some parents expressed was that removing anonymity would in turn remove their control on whether, or when, they informed their children of their donor origins, and that parents were in the best position to assess what was best for their child.

It is important to recognize that DI allows the family to fit into an apparent cultural norm and expectation of genetic connectivity, and it is an important factor in the decision, for many couples, to choose DI. Not disclosing DI status allows a couple to pretend that their children are genetically related to both parents. The fact that male infertility and infertility treatment through DI is still considered highly stigmatized should be recognized by practitioners in this area. Research has shown long-term psychological effects on men of male infertility, raising doubts about masculinity and sexual adequacy [3, 42, 43]. As Kirkman has argued, the need for donor gametes is interpreted as failure by some men and women, and this must be considered in the fact that some parents may choose not to disclose [44]. In previous studies, 'secrecy' has been interpreted as protecting a number of different parties in the DI process. The desire to protect partners and children from negative reactions from others has been reported elsewhere [17, 22, 27, 30, 43-45]. Although legislation can prescribe who is legally the father, there can be little doubt that this does not remove uncertainty around social and personal paternal relationships of social fathers. The symbolic presence of the donor and the emotional impact of conception by DI cannot be underestimated. Sociological analysis of qualitative data from research conducted in the United Kingdom and Australia reveals the complexity of the symbolic presence of the donor in the lives of parents of DI offspring [7,8]. Although the authors of these studies make no claims for the generalizability of their findings, it is likely that these issues have some relevance for individuals across different social and cultural groups.

Research conducted in the United States concluded that the decision to disclose or not the use of DI did not affect parental bonding with the child [30]. There is no evidence that harm is caused by not disclosing DI origins $[30,46]$. Studies that have focussed on the emotional and behavioral development of donor offspring children have not revealed that children show any behavioral or emotional problems [22, 23, 47]. Comparative studies between DI, IVF, adopted and naturally conceived children revealed that the quality of parent-child relationships in DI, IVF and adoptive families were 'better' than those in the families with children conceived naturally (using standardized tests and observation studies). There were no significant differences in the social and emotional development of children [48, 49]. However, these studies were conducted on young children, and caution is required in interpreting these findings for the longer-term development of children [22]. Hence, although there may be no negative impact on early child development from not knowing the details of their conception, this is likely to change as the child becomes older and reaches adulthood. Similarly, concerns are also raised about the high degree of nonparticipation of heterosexual DI families in research $[49,50]$. It is also worth noting that fathers were not part of the original observational studies used, and this is unfortunate given that it is fathers who lack the genetic link with DI children and are more likely to experience difficulties in relating to their children. 


\section{Conclusion}

Policy makers and practitioners in the area do well to consider what an emphatic promotion of rights means in practice for parents of DI offspring. The concerns raised above suggest that the moral sentiment of putting the child's 'rights' first does not address the complexity of family dynamics. Even though the acceptance and attitude to DI generally varies across different cultural and religious groups, the preservation of anonymity allows control for parents on what, when, how and even whether to tell their children of their DI status, and this is likely to have significance for many couples in their decision making about DI.

Findings from previous studies suggest that anonymity is important to parents of DI children on various levels, and practitioners need to be aware of the social significance of anonymity in the advice that they are giving potential parents. In particular, they should recognize that (1) anonymity provides distance from and depersonalizes the donor for the women receiving another man's sperm. The symbolic link between receiving donor sperm and adultery has been made elsewhere [35], and this may have more importance for some potential parents than others; (2) anonymization also provides distance for parents who were reminded that they do not have a biological link with their children; (3) fathers may feel threatened by the donor, and anonymity provides a barrier from the stigma of male infertility. For some, that stigma extends to protecting children from the stigma of being the product of infertility treatment and the knowledge that their fathers were not their biological fathers.

The role of not disclosing DI status, therefore, is to override the lack of a genetic link between donor and child and attach the child to the social father in an ostensibly normal two-parent family [51]. This allows a couple to pretend that their children are genetically related to both parents, and allows the family to fit into an apparent cultural norm and expectation of genetic connectivity. As the findings in previous studies suggest, the desire to replicate a 'natural family' is reflected in the numbers of parents who decide not to tell their children how they were conceived and this leads to the heart of the ethical concerns raised by removing anonymity from sperm donors.

If there are lessons to be learnt from the Western countries that have removed anonymity from sperm donors, it is that decisions to reveal DI origins are highly complex and relate to a range of social and cultural attitudes that are not considered within policy to remove anonymity from sperm donors. This is not to argue that DI offsprings should not be made aware of the circumstances of their conception, and earlier rather than later [52], but rather argues about policy that removes control from parents and attempts to prioritize one set of rights over others, and does not address the real ethical issues at the heart of this matter. Assumptions about a child's right to know his/ her genetic identity fail to address the reasons why anonymity is so important to so many parents in the first place.

\section{References}

1 Gong D, Liu YL, Zheng Z, Tian YF, Li Z. An overview on ethical issues about sperm donation. Asian J Androl 2009; 11: 645-52.

2 Haimes E, Daniels K. International social science perspectives on donor insemination: an introduction. In: Daniels K, Haimes E, editors. Donor Insemination International Social Science Perspectives. Cambridge: Cambridge University Press; 1998.

3 Daniels KR, Lewis GM. Donor insemination: the gifting and selling of semen. Soc Sci Med 1996; 42: 1521-36.

4 Becker G. The Elusive Embryo: How Women And Men Approach New Reproductive Technology. Berkeley: University of California Press; 2000.

5 Hargreaves K. Constructing families and kinship through donor insemination. Sociol Health Illn 2006; 28: 261-83.

6 Grace V, Daniels K. The (ir)relevance of genetics: engendering parallel worlds of procreation and reproduction. Sociol Health Illn 2007; 29: 692-710.

7 Burr J. Fear, fascination and the sperm donor as 'abjection' in interviews with heterosexual recipients of donor insemination. Sociol Health Illn 2009; 31: 705-18.

8 Donovan C. It's not really seen as an issue, you know, lesbian infertility its kind of 'what's that?': lesbians' unsuccessful experiences of medicalised donor insemination. Med Sociol Online 2008; 3: 15-24.

9 Schenker JG, Shushan A. Ethical and legal aspects of assisted reproduction practice in Asia. Hum Reprod 1996; 4: 908-11.

10 McWhinnie A. Gamete donation and anonymity. Hum Reprod 2001; 16: 807-17.

11 Warnock Report. The Report of the Committee of Inquiry into Human Fertilisation and Embryology. London: HMSO; 1984.

12 Haimes E. Recreating the family? Policy considerations relating to the 'new' reproductive technologies. In: McNeil M, Varcoe I, Yearly S, editors. The New Reporductive Technologies. Basingstoke: Macmillan; 1990 .

13 Available from: http://www.timesonline.co.uk/tol/news/ science/article4215440.ece. June 26, 2008 [cited 29 March 2010].

14 Sheldon S. Fragmenting fatherhood: the regulation of 
reproductive technologies. Mod Law Rev 2005; 68: 523-55.

15 Blyth E, Hunt J. Sharing genetic origins information in donor assisted conception: views from licensed centres on HREA donor information form 4. Hum Reprod 1998; 13: 3274-7.

16 Frith L. Gamete donation and anonymity: the ethical and legal debate. Hum Reprod 2001; 16: 818-24.

17 Snowden R, Mitchell GD, Snowden EM. Artificial Reproduction: A Social Investigation. London: George Allen and Unwin, 1983.

18 Bellis M, Hughes K, Hughes S, Ashton J. Measuring paternal discrepancy and its public health consequences. J Epidemiol Community Health 2005; 59: 749-54.

19 Shenfield F, Steele DJ. What are the effects of anonymity and secrecy on the welfare of the child in gamete donation? Hum Reprod 1997; 12: 392-5.

20 Blyth E, Frith L. The UK's gamete donor 'crisis' - a critical analysis. Crit Soc Policy 2008; 28: 74-95.

21 Adams J, Pease E, Lieberman B. Donor recruitment: change attitudes not the law. Bionews, 16 October 2006. [cited 12 June 2010]. Available from: http://www.bionews.org.uk/ page_37904.asp).

22 Brewaeys A, Golombok S, Naaktgeboren N, de Bruyn J, van Hall E. Donor insemination: Dutch parents' opinions about confidentiality and donor anonymity and the emotional adjustment of their children. Hum Reprod 1997; 12: 1591-7.

23 Brewaeys A. Donor insemination, the impact on family and child development. J Psychosom Obstet Gynaecol 1996; 17: 1-13.

24 Leiblum SR, Aviv AL. Disclosure issues and decisions of couples who conceived via donor insemination. J Psychosom Obstet Gynaecol 1997; 18: 292-300.

25 Golombok S, Breaeys A, Giavazzi MT, Guerra D, MacCallum F, Rust J. The European study of assisted reproduction families: The transition to adolescence. Hum Reprod 2002; 17: $830-40$.

26 Söderström-Anttila V, Foudila T, Ripatti UR, Siegberg R Embryo donation: outcome and attitudes among embryo donors and recipients. Hum Reprod 2001; 16: 1120-8.

27 Cook R, Golombok S, Bish A, Murray C. Disclosure of donor insemination: parental attitudes. Am J Orthopsychiatry 1995; 65: 549-59.

28 Gottlieb C, Lalos O, Lindblad F. Disclosure of donor insemination to the child: the impact of Swedish legislation on couples' attitudes. Hum Reprod 2000; 15: 2052-6.

29 Walker A, Gregson S, McLaughlin E. Attitudes towards donor insemination- a post Warnock survey. Hum Reprod 1987; 2: 745-50.

30 Daniels KR, Taylor K. Secrecy and openness in donor insemination. Politics Life Sci 1993; 12: 155-70.

31 Klock SC, Jacob NC, Maier DA. A prospective study of donor insemination recipients: secrecy, privacy, and disclosure. Fertil Steril 1994; 62: 477-84.

32 Purdie A, Peek JC, Irwin R, Ellis J, Graham FM, Fisher PR. Identifiable semen donors-attitudes of donors and recipient couples. NZ Med J 1992; 105: 27-8.

33 Brewaeys A, Ponjaert-Kristoffersen I, Van Steirteghem A, Devroey P. Children from anonymous donors: an inquiry into homosexual and heterosexual parents' attitudes. J
Psychosom Obstet Gynaecol 1993; 14: 23-35.

34 Snowden R, Mitchell G. The artificial family: a consideration of artificial insemination by donor. London: George Allen and Unwin; 1981.

35 Snowden R, Snowden E. The Gift of a Child. Exeter: University of Exeter Press; 1993.

36 Baran A, Pannor R. Lethal Secrets. New York: Warner Books; 1989

37 McWhinnie A. Creating children: the medical and social dilemmas of assisted reproduction. Early Child Dev Care 1992; 81: 39-54.

38 McWhinnie A. Families from assisted conception: ethical and psychological issues. Hum Fertil 2000; 13: 13-9.

39 Burr J, Reynolds P. Thinking the right to genetic inheritance: liberal rights, communitarianism and the right to privacy for parents of DI children. J Med Ethics 2008; 34: 281-4.

40 Daniels KR, Lewis GM, Gillet W. Telling donor insemination offspring about their conception: the nature of couples' decision-making. Soc Sci Med 1995; 40: 1213-20.

41 Looi K. Donor Insemination: Which Families Tell? In: Jansen R, Mortimer D, editors. Towards Reproductive Certainty: Fertility and Genetics Beyond 1999. Lancashire: Parthenon; 1999. pp145-56.

42 Miall C. The stigma of involuntary childlessness. Soc Probl 1986; 33: 268.

43 Kirkman M. Parents' contributions to the narrative identity of offspring of donor-assisted conception. Soc Sci Med 2003; 57: 2229-42.

44 Rowland R. The social and psychological consequences of secrecy in artificial insemination by donor (AID) programmes. Soc Sci Med 1985; 21: 391-6.

45 Nachtigall RD, Tschann JM, Quiroga SS, Pitcher L, Becker G. Stigma, disclosure, and family functioning among parents of children conceived through donor insemination. Fertil Steril, 1997; 68: 83-9.

46 Pennings G. The 'double track' policy for donor anonymity. Hum Reprod 1997; 12: 2839-44.

47 Kovacs G. The Use of Donor Insemination. The Subfertility Handbook: A Clinicians' Guide. Cambridge: Cambridge University Press; 1997. pp139-50.

48 Golombok S, Cook R, Bish A, Murray C. Families created by the new reproductive technologies: quality of parenting and social and emotional development of the children. Child Dev 1995; 64: 285-8.

49 Golombok S, Brewaeys A, Cook R, Giavazzi MT, Guerra D, et al. The European study of assisted reproduction families: family functioning and child development. Hum Reprod 1996; 11: 101-8.

50 Snowden R. Snowden E. Families created through donor insemination. In: Daniels K, Haimes E, editors. Donor Insemination: International Social Science Perspectives. Cambridge: Cambridge University Press; 1998 .

51 Haimes E. Issues of gender in gamete donation. Soc Sci Med 1993; 36: 85-93.

52 Jadva V, Freeman T, Kramer W, Golombok S. The experiences of adolescents and adults conceived by sperm donation: comparisons by age of disclosure and family type. Hum Rprod 2009; 24: 1909-19. 